\title{
REASSEMBLY OF ROCK SEGMENTS, THE CASE OF AREOPAGUS HILL
}

\author{
V. Evgenikou ${ }^{1}$, A. Georgopoulos ${ }^{2}$, M. Korres ${ }^{3}$ \\ ${ }^{1}$ MSc Surveyor Engineer NTUA, Athens, Greece, vevge@hotmail.com \\ ${ }^{2}$ Professor, Lab. Of Photogrammetry NTUA, Athens, Greece, drag@central.ntua.com \\ ${ }^{3}$ Professor Emeritus NTUA, Academy of Athens, Athens, Greece, mankor@otenet.gr
}

\section{Commission II}

KEY WORDS: 3d models, SfM, virtual reconstruction, collapsed rocks, reassembly, rock-cut monuments

\begin{abstract}
:
There are no specifications and/or standards for the restoration of collapsed masses of rocks, as in most cases the rocks bear no historical/archaeological value and their restoration would require significant budget and resources. But plenty of colossal statues, ancient temples, tombs and whole cities are carved on the surface or even expand in the interior of solid natural rocks. These so-called rock-cut monuments are located all around the globe and, in most cases, are made on a grand scale.

Earthquakes, rock's faults, erosion and karst can lead to massive rock collapses. The purpose of this paper is to establish an integrated methodology for the relocation of detached rock segments to their original positions. Specifically, the proposed methodology is based on the case of the Areopagus Hill and involves the generation of $3 \mathrm{~d}$ models of the rock segments, their virtual reassembly and their utilization for the reconstruction of a part of the peak of the hill.
\end{abstract}

\section{INTRODUCTION}

\subsection{Historical background}

Areopagus Hill is located at the west of the Acropolis and has been a major landmark in the city of Athens for more than 5000 years. Remains from ancient buildings scattered on its surface or located at the area around the hill provide important archaeological information about the urban evolution of the city throughout the centuries.

The boundaries of Athens kept changing, according to its wealth. In times of prosperity, the city expanded and Areopagus Hill became a domestic place, containing civic buildings and religious shrines. Monuments from those periods are the remains of the settlement Melete Deme [Camp, 2004] and the traces of the foundation of an Ionic temple of the 5th century BC., located on the top of the hill [Korres, 1996]. On the contrary, in times of decline, Athens' urban space was limited and Areopagus Hill was on or even outside the city's boundary. The remains of the socalled philosophical schools [Frantz, 1988] from late Roman antiquity and the wall of Haseki [Stathi, 2014] from the Ottoman times are dated to such periods.

Nevertheless, Areopagus Hill has been highly connected with religion. From antiquity, the hill was linked with Dodekatheism, in an effort to enhance the prestige of the institution of the court of Areopagites who gathered there. Nowadays, it is widely believed that Apostle Paul preached at Areopagus Hill at 51 AD and established Christianity in Attica.

All this lead to the conclusion that Areopagus Hill is a monument of great archaeological and historical value and should be protected and conserved.

\subsection{Karst and erosion}

The endurance of every structure depends on the properties of the used materials. When it comes to monuments that consist of stone blocks or are carved on rock, their strength and durability depends mainly on the rocks' quality, which is affected by faults, such as cracks and discontinuities.

In the case of Areopagus Hill the monument's main geological element, the Athenian hard limestone, has too many discontinuities [Andronopoulos \& Koukis, 1976] that allow the intrusion of rainwater. Consequently, the rock has been eroded by dissolution (karst) and cavities and other karstic forms have been produced in its interior that decreased the limestone's volume, strength and durability.

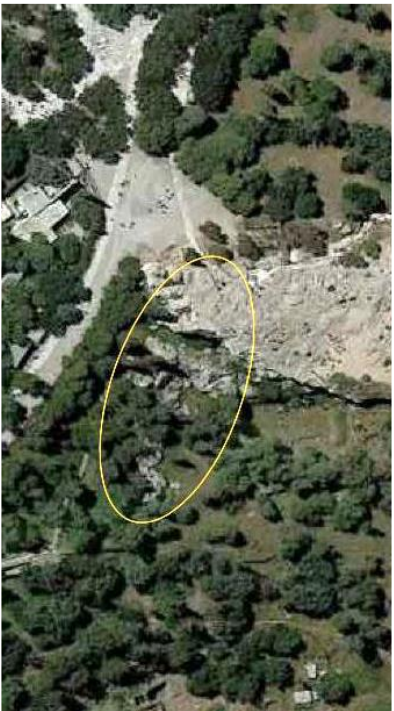

(a)

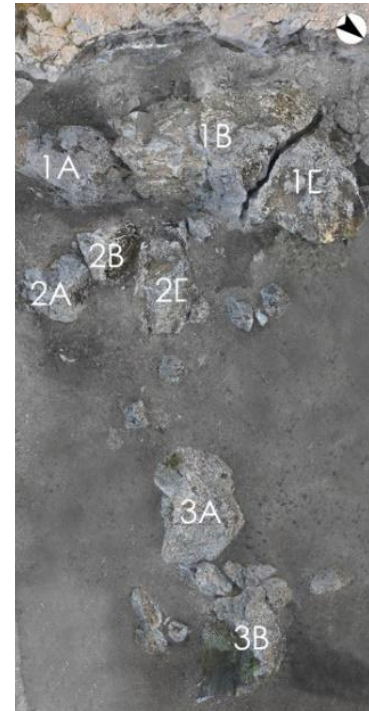

(b)
Figure 1: The collapsed peak of the hill. (a) Aerial photograph, (b) Ground plan orthoimage of the investigated area.

Additionally, the limestone is seated on a layer of schist, which is corroded more rapidly than limestone. As a result, as centuries passed by, schist 'shrunk' towards the center of the hill and the limestone formed cantilevers a few meters above the ground level that gradually collapsed. 
From antiquity until nowadays these geological issues along with numerous earthquakes have drastically changed the form of Areopagus Hill. A part from the peak of the hill, which contained carved foundation trenches of the Ionic temple, collapsed probably due to a great earthquake that took place in the 18th century [Acropolis Restoration Service, 2017]. A rock-mass that weighted around 4000 tons was detached from the hill and crumbled (Figure 1). This paper deals with the rocks located in this area and their reassembly.

As weathering and karstification of the hill carry on, pieces of limestone will keep collapsing from Areopagus Hill. Therefore, measures should be taken in order to restore and preserve both the monument and the landscape.

\section{RELATED WORKS}

The most well-known example of a reassembly of rock-cut monuments is the case of the Great Temple and of the Temple of Hathor and Nefertati at Abu Simbel that took place in 1964 by the Egyptian Ministry of Culture with the assistance of UNESCO. The monuments had to be moved to another location in order to be saved from the rising waters of the Lake Nasser, caused by erection of the Aswan High Dam. Due to their large scale and heaviness, the monuments along with a major part the sandstone cliff on which they were carved had to be sawed into blocks weighting up to 30 tons. After the dismantling, the blocks were lifted and reassembled in a new location $208 \mathrm{~m} \mathrm{NW}$ and $65 \mathrm{~m}$ above their previous site [Berg, 1978].

The resemblance of the case of Abu Simbel with the restoration of Areopagus Hill is that in both cases the heaviness of the monuments leave no choice but to divide them into large stone blocks prior to their lifting. In order to cause minimum damage and to be able to rebuild them, vertical and horizontal cutting planes are chosen and determined in detail before the cutting actually starts. The criteria taken into account are archaeological, aesthetic, technical and economic.

In this paper some crucial steps of the methodology applied in the case of Abu Simbel are updated through the utilization of the technological advances of the last decades.

\section{DEVELOPED METHODOLOGY}

\subsection{Generation of $\mathbf{3 d}$ models}

The creation of textured $3 \mathrm{~d}$ models was essential for the virtual reconstruction of the hill's collapsed part, as they were necessary for the virtual reassembly of the rock masses, for the calculation of their weight and for the definition of the cutting-planes.

Areopagus Hill presented severe difficulties for its $3 d$ reconstruction. The monument's size and complexity, the steep slopes, the wide cracks, the discontinuities, the narrow passages, the vegetation and the numerus tourists visiting the archeological site, made the creation of an accurate and complete $3 \mathrm{~d}$ model very challenging. Under these circumstances flexibility and rapidity were essential, thus, image based methods have been applied for $3 \mathrm{~d}$ reconstruction.

Image acquisition was very carefully planned, in order to ensure best results. Approximately 3,500 images were taken with a Nikon D750 full frame DSLR with a resolution of 24 Mpixel and a $28 \mathrm{~mm}$ Tamron lens. In order to photograph the slopes, the camera was attached to a patented $5 \mathrm{~m}$ long mast (Figure $2 \mathrm{~b}$ ). Additionally, around 30 targets were measured geodetically (Figure 2a) in order to control the accuracy of the photogrammetric processing. The textured $3 \mathrm{~d}$ model of the area was created via the Photoscan software by Agisoft and is presented in Figure 3.

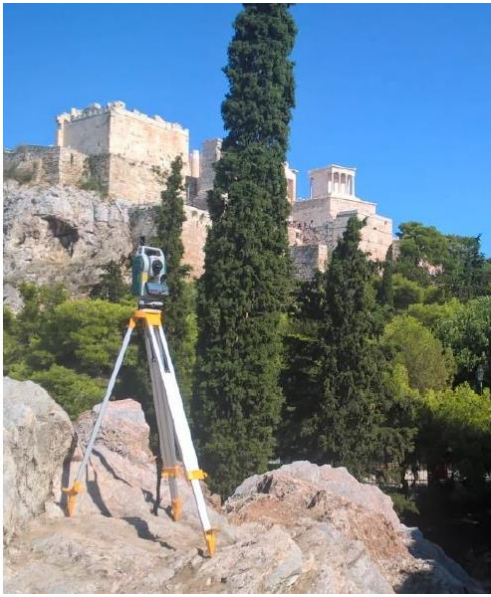

(a)

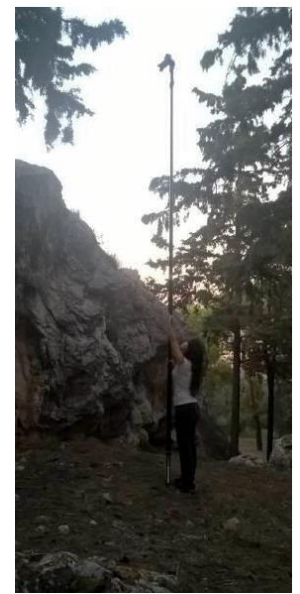

(b)
Figure 2: Data acquisition. (a) The total station used to measure the coordinates of the targets, (b) The camera attached to the patented mast.

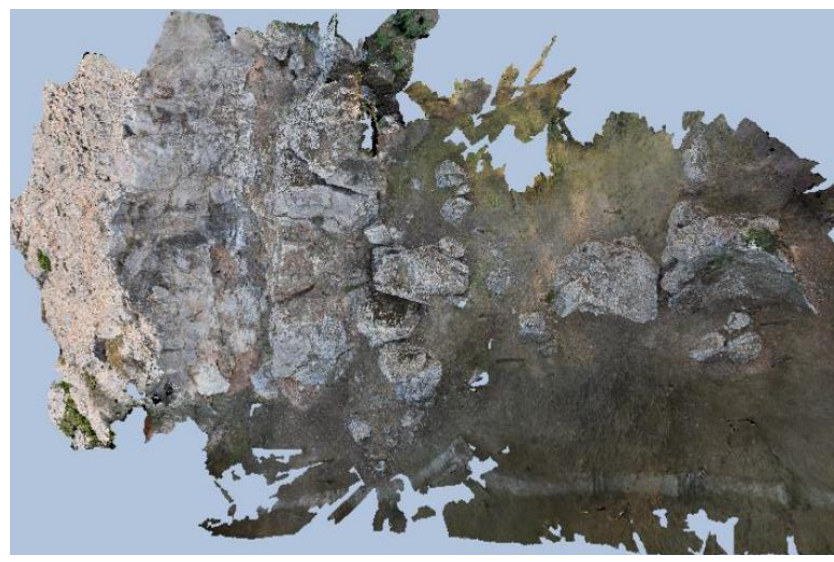

Figure 3: The textured 3d model of the Areopagus peak and the collapsed rock masses.

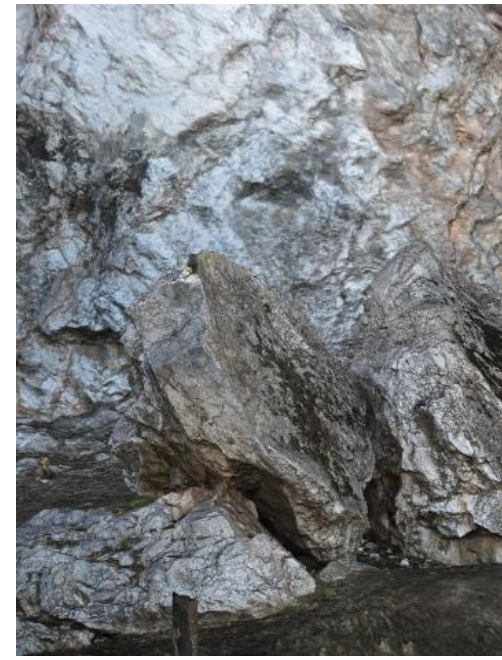

(a)

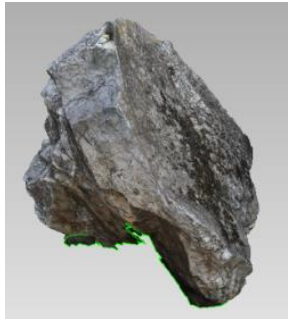

(b)

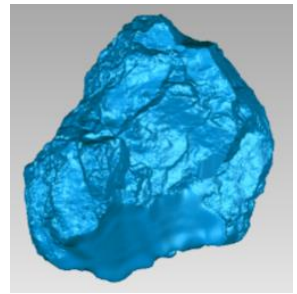

(c)
Figure 4: Generation of the $3 \mathrm{~d}$ model of rock $2 \mathrm{~B}$. (a) The $3 \mathrm{~d}$ model of rock $2 \mathrm{~B}$ and of the surrounding area, (b) The cropped sub-model, (c)The closed volume of the sub-model. 
The next step took place in the environment of the software Geomagic Studio 2014 and was the division of the $3 \mathrm{~d}$ model into 9 sub-models: one for the hill-cliff and one for each of the larger collapsed rocks found in the area. The model of each rock was selected and cropped from the main model of the area. As shown in Figure 4, it is noted that all the meshes' holes were closed in order to be able to approximately compute the rock's volumes and, by extension, to estimate their weight. As for the model of the hill-cliff it emerged from the remaining mesh.

\subsection{Correlations among the rock mashes and the hill}

In order to figure out the original positions of the collapsed rock masses, prior to their detachment, several geological features were investigated and recorded on the field, such as calcareous deposits and their characteristics (layer thicknesses, presence of crystals etc.), karstic forms, cavity traces and stalagmites. Some of those features contributed to the connection of the collapsed rocks with each other or/and with the Areopagus Hill, while others led to the assumption of their original orientations.

Specifically, joints were found among the cliff and the rocks $1 \mathrm{~A}$, $1 \mathrm{~B}, 1 \mathrm{C}$ and $2 \mathrm{~A}$. Rocks $2 \mathrm{~B}$ and $2 \mathrm{C}$ were connected to each other and set to their original orientation, while rocks $3 \mathrm{~A}$ and $3 \mathrm{~B}$ were only orientated. All the orientations were determined via the stalagmites that were found on the rocks, as stalagmites are formed strictly vertically, while they aren't too close at the cavities walls.

During research for correlations among the rocks, traces of intense quarrying activity were detected. Three triangular holes were drilled for the insertion of powdered explosive as part of stone extraction process in the mid. 19th century. Other traces of quarrying are carved sockets for wedges left on the surface of the rocks, after being used to split them from the bedrock. These findings along with the fact that the total volume of the collapsed rocks is about $2 / 3$ of the expected, led to the conclusion that the collapsed rocks must have been used as building material for the construction of the nearby residences, probably during $18^{\text {th }}-19^{\text {th }}$ century.

But not all the missing rocks have been removed from the area. Some are still buried in the ground [Frantz, 1988]. So, excavation is necessary to reveal all the remaining parts of the hill that should be taken into account while planning the restoration of the monument. Therefore, the next paragraphs deal only with the reassembly of the rocks $1 \mathrm{~A}, 1 \mathrm{~B}$ and $1 \mathrm{C}$ with the hill, as they compose the bottom of the missing part of the monument and, regardless of the fragments that the excavation will reveal, their relocation and restoration will not be revised.

\subsection{Virtual reconstruction}

The $3 \mathrm{~d}$ models of the hill-cliff and of the three larger rock masses (1A, 1B \& 1C), were virtually assembled via Geomagic Studio 2014 software. Common points were marked and the models were automatically aligned roughly, as shown on the example of Figure 5, and, if needed, the alignment was corrected manually, as, due to erosion of the fragments, the automated procedure didn't always lead to the desired result and the meshes ended up intersecting each other.

The virtual reconstruction that resulted in the aligned $3 \mathrm{~d}$ models is presented in Figure 6. An important observation was made through this process: At the bottom of the hill was a small cave, which could be related to a grotto-shrine of Semnes deities and is mentioned in ancient literary sources to be located at Aeropagus
Hill [Lardinois, 1992]. Additionally, it is clear from Figure 6c that the ground level has significantly raised since the collapse.

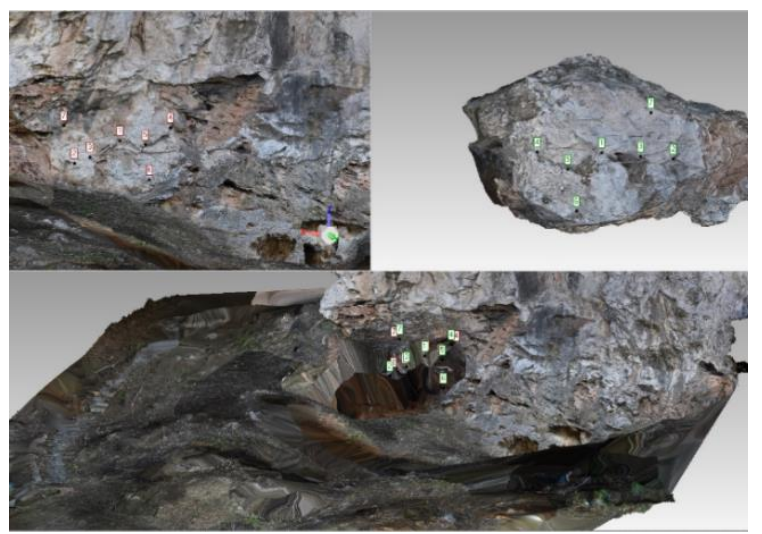

Figure 5: Alignment of the model of the hill-cliff and the rock $1 \mathrm{~A}$.

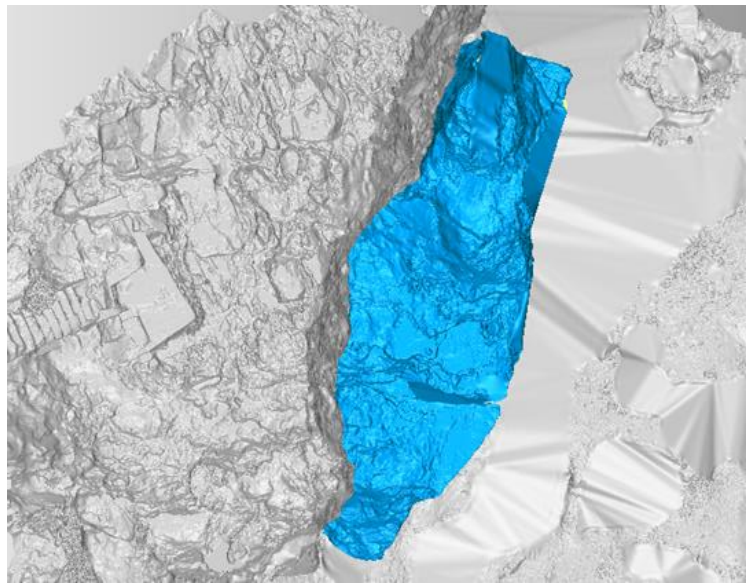

(a)

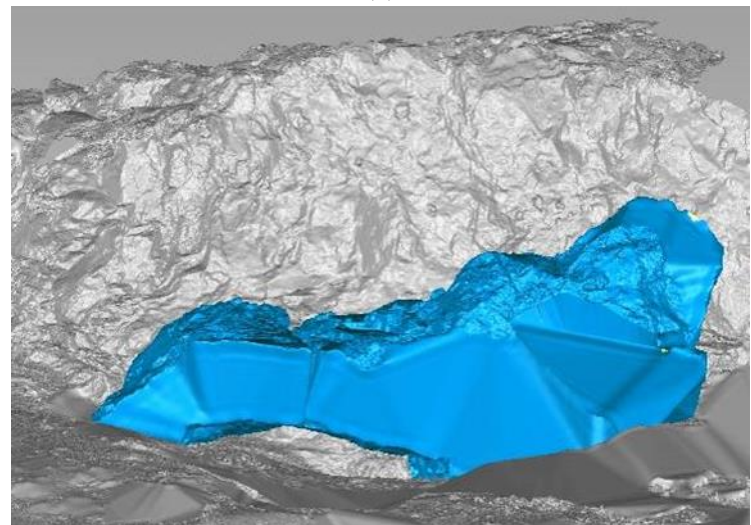

(b)

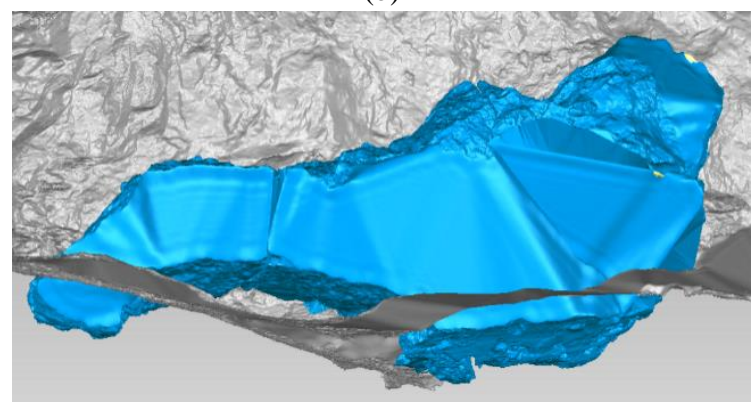

(c)

Figure 6: The result of the virtual reconstruction in shaded view; aligned models appear in blue color, (a) ground plan, (b) perspective view, (c) elevation facing SW. 


\subsection{Virtual cutting of rock masses}

The weight of the rocks sets many technical limitations to the reconstruction of the monument. In order to actually reconstruct the hill, the large rock fragments have to be divided in pieces so that cranes can lift and place them to their original positions. For this purpose, horizontal and vertical cutting planes were defined on the aligned $3 \mathrm{~d}$ models of the rocks $1 \mathrm{~A}, 1 \mathrm{~B}$ and $1 \mathrm{C}$. The main criteria were the geometry and the weight of the rocks and the creation of the minimum amount of segments. Each rock was divided to 5-13 parts that weighed a max of 80 tons, a weight that a moderate crane can lift.

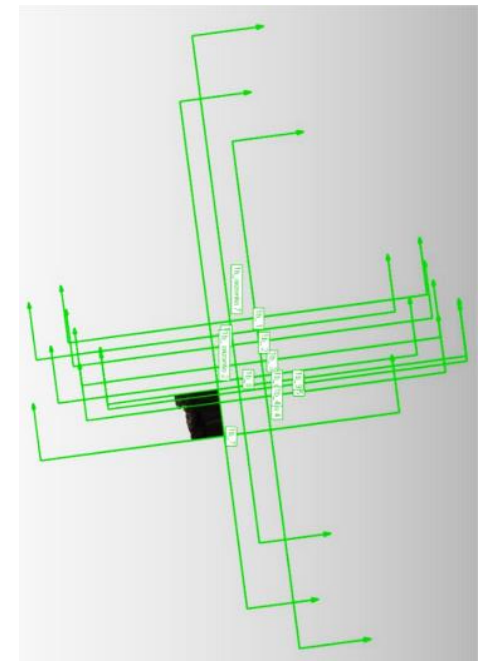

(a)

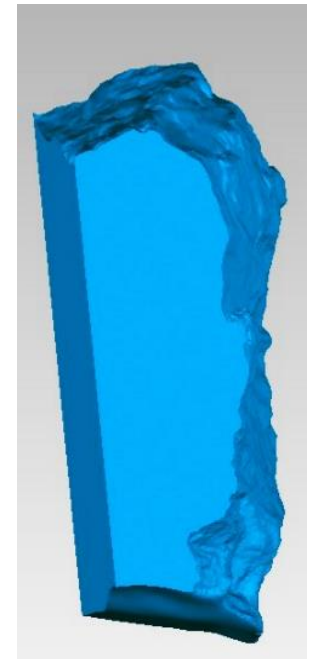

(b)
Figure 7: The virtual cutting of rock 1B. (a) The cutting planes, (b) An example of a rock segment.

The virtual cutting and the calculation of the weight of each rock segment took place in the Geomagic Studio 2014 software. The procedure was repeated until the optimum result was achieved:

- A vertical or horizontal plane was defined by selecting a point on the aligned model.

- The model was trimmed via that plane.

- The hole of the remaining mesh was closed with a flat surface (Figure 7b).

- The segment's volume was automatically calculated.

- The segment's weight was manually calculated, assuming that $1 \mathrm{~m}^{3}$ of limestone weights $2,5 \mathrm{tn}$.

- If the weight wasn't within an acceptable range of values, the plane was offset accordingly. Otherwise, the next plane was defined.

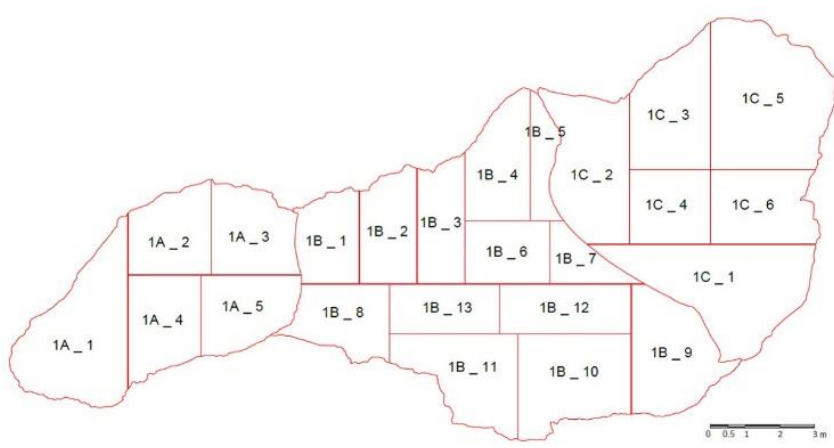

Figure 8: The positions and the code names of the rock segments. Elevation facing SW.
It has to be noted that for the generation of the model of a rock segment 1-4 planes were used. The 12 planes needed for the cutting of rock 1B are presented in Figure 7a.

The virtual cutting resulted in a total of 20 planes and 24 rock segments (Figure 8). The volume and the weight of each segment is shown in table 1 .

\begin{tabular}{|c|c|c|}
\hline $\begin{array}{c}\text { SEGMENT'S } \\
\text { CODE NAME }\end{array}$ & $\begin{array}{c}\text { VOLUME } \\
\left(\mathrm{m}^{3}\right)\end{array}$ & $\begin{array}{c}\text { WEIGHT } \\
\text { (tn) }\end{array}$ \\
\hline 1A_1 & 31,131 & 77,827 \\
1A_2 & 28,287 & 70,717 \\
1A_3 & 28,734 & 71,835 \\
1A_4 & 23,831 & 59,578 \\
1A_5 & 23,665 & 59,163 \\
\hline 1B_1 & 30,777 & 76,942 \\
1B_2 & 30,829 & 77,071 \\
1B_3 & 30,042 & 75,106 \\
1B_4 & 29,928 & 74,820 \\
1B_5 & 29,801 & 74,504 \\
1B_6 & 30,451 & 76,128 \\
1B_7 & 30,098 & 75,245 \\
1B_8 & 30,338 & 75,845 \\
1B_9 & 30,343 & 75,857 \\
1B_10 & 30,627 & 76,567 \\
1B_11 & 30,094 & 75,236 \\
1B_12 & 30,532 & 76,331 \\
1B_13 & 29,880 & 74,699 \\
\hline 1C_1 & 27,779 & 69,447 \\
1C_2 & 27,873 & 69,682 \\
1C_3 & 27,358 & 68,394 \\
1C_4 & 27,502 & 68,754 \\
1C_5 & 28,172 & 70,430 \\
1C_6 & 27,605 & 69,012 \\
\hline total & 695,676 & 1739,191 \\
\hline
\end{tabular}

Table 1: Volume and weight of each rock segment.

However, during the actual reconstruction of the Areopagus Hill, the collapsed rocks would have to be cut at their current positions while the cutting planes have been defined to their aligned ones. Three 3d transformations took place, one for each rock, and the planes were transferred from the aligned models to the present ones. These transformations were performed in Cloud Compare software, while Geomagic Studio 2014 was used for the preliminary work. Specifically, for each aligned model:

- One curve was created from the section of the $3 \mathrm{~d}$ model with each cutting plane.

- Dense point clouds were extracted from each curve

- The unnecessary points were erased and the remaining were combined into a single point cloud

- Two 3d models were inserted in Cloud Compare: The original $3 \mathrm{~d}$ model of the collapsed rock and the $3 \mathrm{~d}$ model generated from the corresponding cutting planes

- The two models were automatically aligned while the rock's $3 \mathrm{~d}$ model remain fixed

- $\quad$ The aligned $3 \mathrm{~d}$ model generated from the corresponding cutting planes was exported from Cloud Compare, inserted into AutoCAD and put together with the ground plan and elevation orthophotos of the rocks $1 \mathrm{~A}, 1 \mathrm{~B}$ and $1 \mathrm{C}$

The result of the pipeline described above is shown in Figure 9 and it is the guide for cutting the collapsed rocks on the field. It has to be noted that in Figure 9 appears also the order in which the cutting has to be performed. The proposed method to divide the rocks is via a diamond wire machine as it is the less destructive method available. 


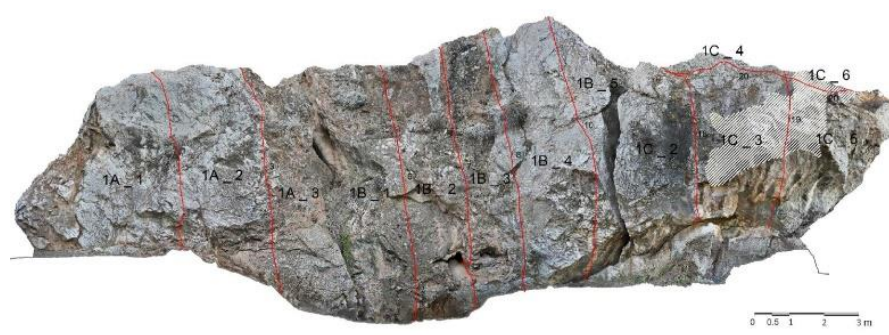

(a)

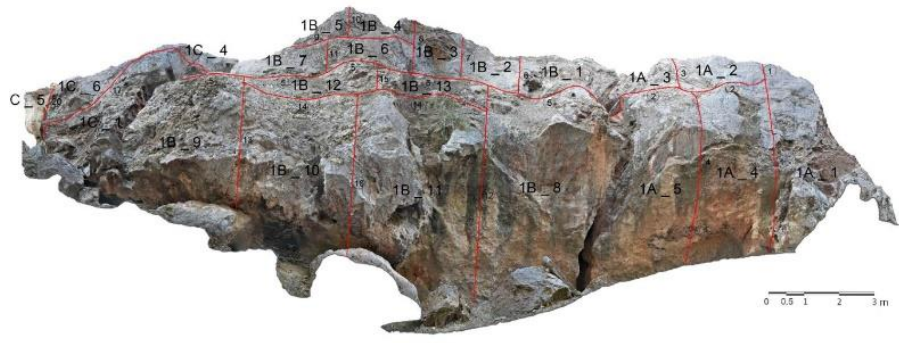

(b)

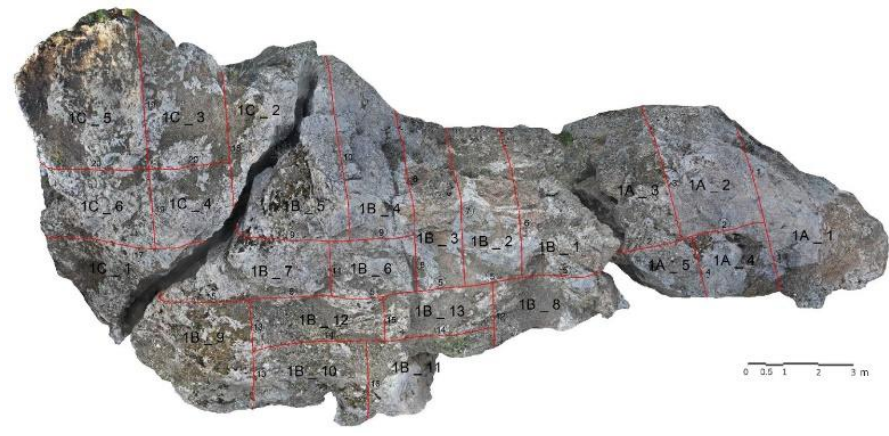

(c)

Figure 9: The result of the virtual cutting, (a) elevation facing SW, (b) elevation facing NE, (c) ground plan.

It should be pointed out that throughout the cutting process the rocks must be secured, as there is a great possibility of inversion, due to the constant removal of segments and modification of the rocks' centers of gravity.

\subsection{Reconstruction of the collapsed part}

As described in paragraph 1.2., due to karst and erosion, the limestone gradually formed cantilevers a few meters above the ground that eventually fell down and crumbled. Consequently, in order to place the collapsed rocks to their original positions, the schist bed, that no longer exists, has to be substituted by an artificial structure on which the rocks will be laid. In addition, the ground level has to be lowered a few meters because it occupies the space where rocks have to be placed (see Figure 6c).

The designed substructure consists of very durable concrete cylindrical posts set in parallel rows, which vary in height. On top of them rests a concrete platform that roughly approaches the outline of the rock masses' bottom. Nevertheless, it comprises of individual horizontal zones on which hydraulic lifting jacks will be placed on pre-defined positions, in order to receive, level and slightly move the rock segments to their final positions.

The sketches in Figure 11 present how each rock segment will be placed on the designed substructure and will receive its final position. Specifically:
- Each individual stone segments from the bottom row (from left to right: 1A_1, 1A_4, 1A_5, 1B_8, 1B_11, 1B_10,1B_9 \& 1C_1, as shown in Figure 8) will be lifted with the crane (Figure 11a). The placement of the crane's straps has to ensure that while on air the segments won't tilt.

- $\quad$ Each segment will be placed on three jacks (Figure 11b). The areas that will rest on the jacks are predefined and shown in Figure 12.

- The levelling of each segment will be achieved through the fluctuation of the jacks' heights (Figure 11c).

- The crane's straps will be removed and the rock's weight will be received only by the three jacks (Figure 11d). Therefore, each jack's lifting capacity has to be at least $25 \mathrm{tn}$.

- The system of the rock segment and the three jacks will be slightly maneuvered horizontally in order to receive the desired position (Figure 11e). The movement will be enabled by sliding the jacks on aluminum strips spread with a thin layer of oil.

- Concrete will be casted so that all areas between the rock and the platform, where a jack has not been placed, will be filled (Figure 11f).

- The jacks and the strips, on which they rest, will be taken away from the structure (Figure $11 \mathrm{~g}$ ). The direction from which the jacks will be ejected, depends on the design of the substructure. As shown in Figure 12 the jacks might be withdrawn either from the short or from the long sides of the segments. Nevertheless, the way that the jacks will be removed, depends on the order that the segments are placed one by one. Only while placing the first rock segment, the jacks can be ejected from both sides, while in every other case the jacks must be withdrawn from one side as on the other side a rock will already be placed blocking the way.

- Concrete will be casted at the areas where the jacks were placed (Figure 11h).

While cutting the rocks material loss is inevitable. Even with the diamond wire machine, a layer $0,8-1 \mathrm{~cm}$ thick is turned into dust with every cutting. So, while a segment is placed to its final position, the distance from the nearby blocks has to be equal to the diameter of the diamond wire. In order to ensure that, spacers will be used prior placing each segment. This condition sets restrictions to the reassembly of the segments that do not belong to the bottom row, as the use of jacks for leveling and micro maneuvering isn't possible in this case.

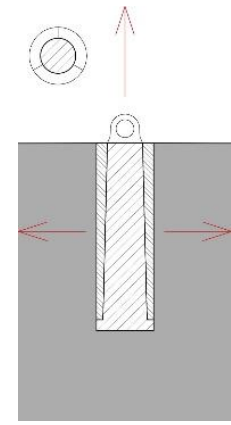

(a)

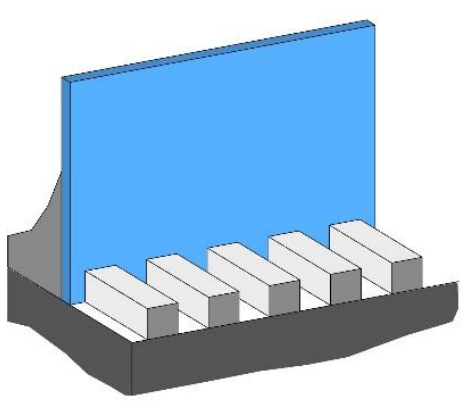

(b)
Figure 10: Placing rock segments from the upper rows. (a) Lewis mechanism, (b) Application of cement on the upper surface of the segment underneath using special aluminum sheet.

For the lifting and placement of the segments at the upper rows a vertical hole will be rotary drilled from the upper side of each block and a lewis mechanism will be inserted (Figure 10a). The 


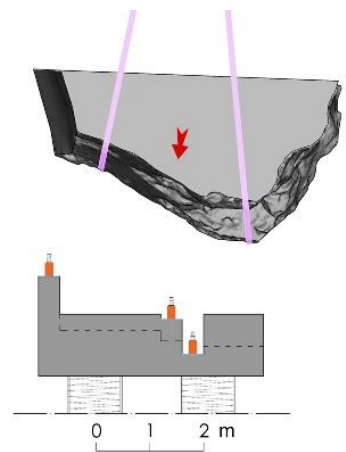

(a)

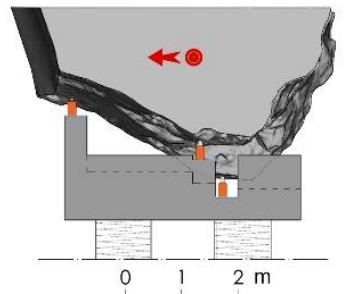

(e)

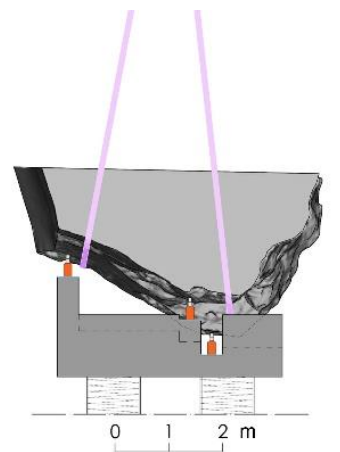

(b)

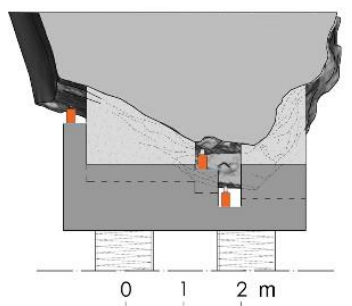

(f)

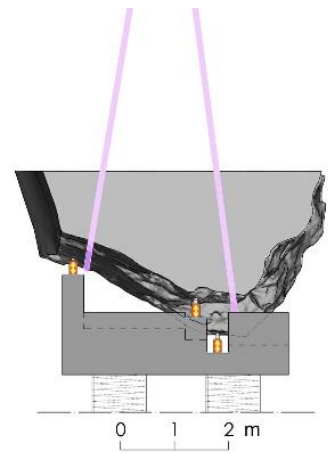

(c)

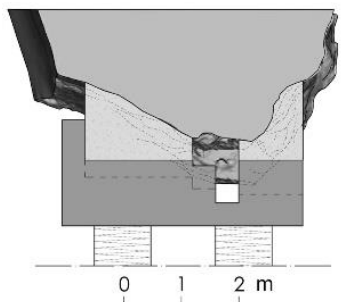

(g)

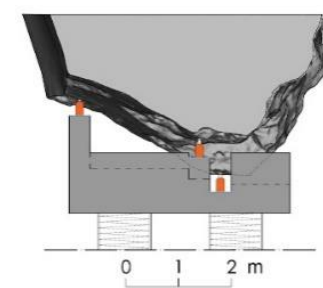

(d)

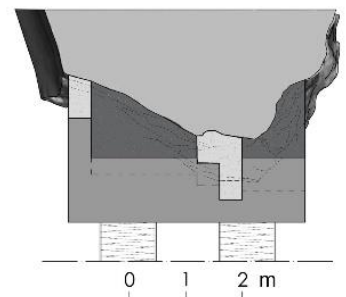

(h)

Figure 11: The steps of the assembly, (a) lifting, (b)placing on three lifting jacks, (c) levelling, (d) detachment of the crane's straps, (e) horizontal micro maneuvering, (f) first concrete casting, (g) removal of the jacks, (h) second concrete casting.

lewis has to be placed above the centre of gravity of the segment in order to avoid titling.

Before placing the segment, concrete has to be applied on the upper surface of the block on which it's going to be placed. The concrete layer has to replace the exact amount of stone, which was lost during cutting with diamond wire. In order to achieve a uniform concrete layer of the desired thickness, a specially shaped aluminum sheet will be used for the application (Figure $10 \mathrm{~b})$. The dimension of the sheet's openings has to be twice the diameter of the diamond wire used for the cutting. When the segment will be placed, its pressure on the concrete strips will lead to the formation of the desired layer.

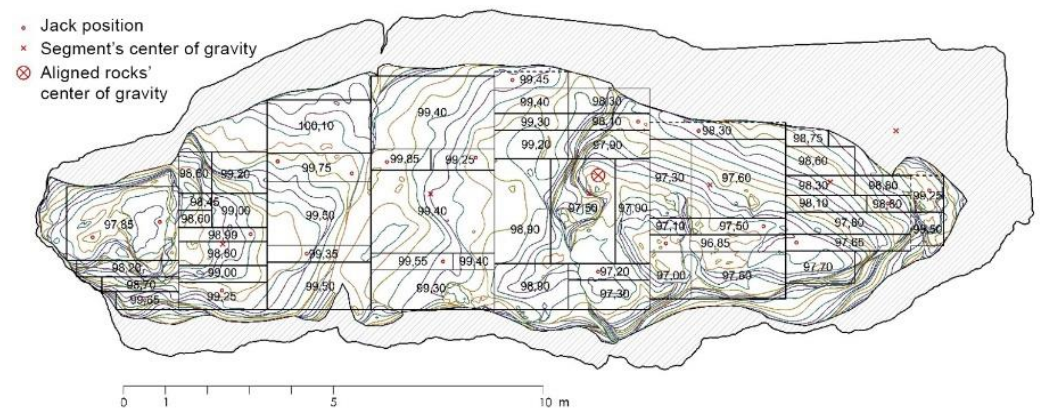

(a)

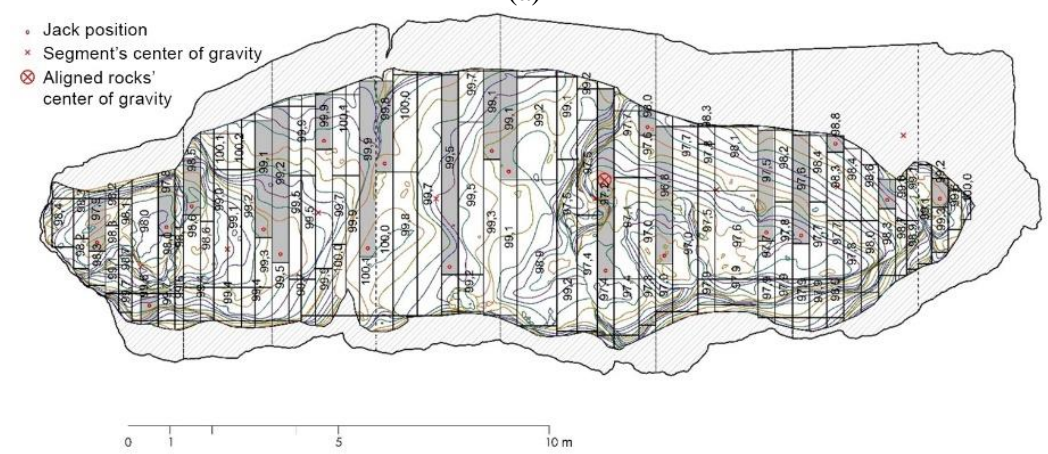

(c)

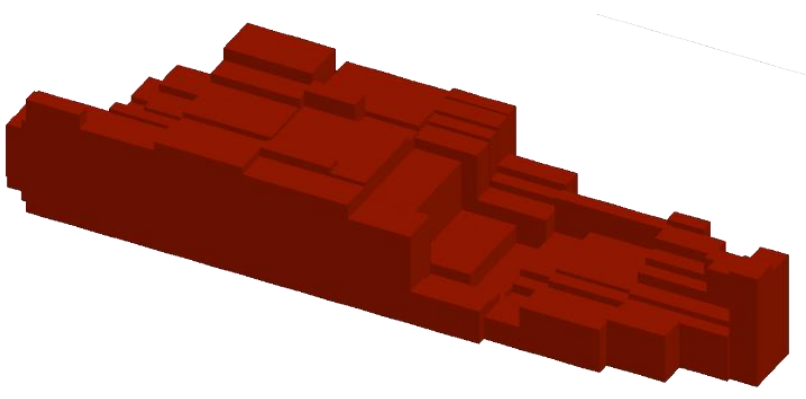

(b)

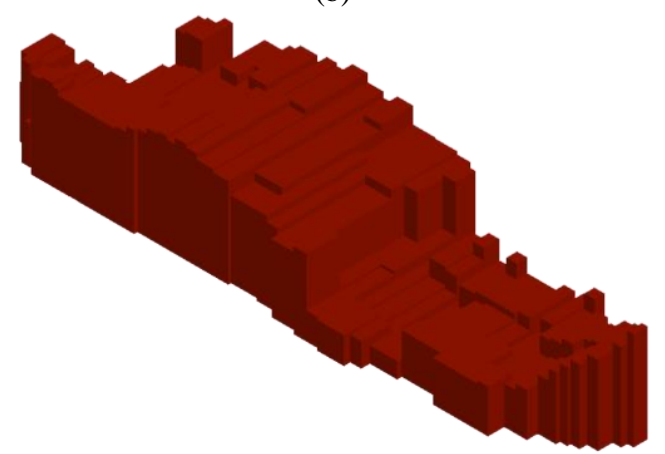

(d)

Figure 12: The upper surface of the substructure. (a) Bottom view of the aligned rocks 1A, 1B \& 1C along with the design of the substructure for the ejection of the lifting jack from the long sides of the rock segments, (b) perspective view of the upper side of the substructure designed for the ejection of the lifting jack from the long sides of the rock segments, (c) Bottom view of the aligned rocks 1A, 1B \& 1C along with the design of the substructure for the ejection of the lifting jack from the short sides of the rock segments, (d) perspective view of the upper side of the substructure designed for the ejection of the lifting jack from the short sides of the rock segments. 

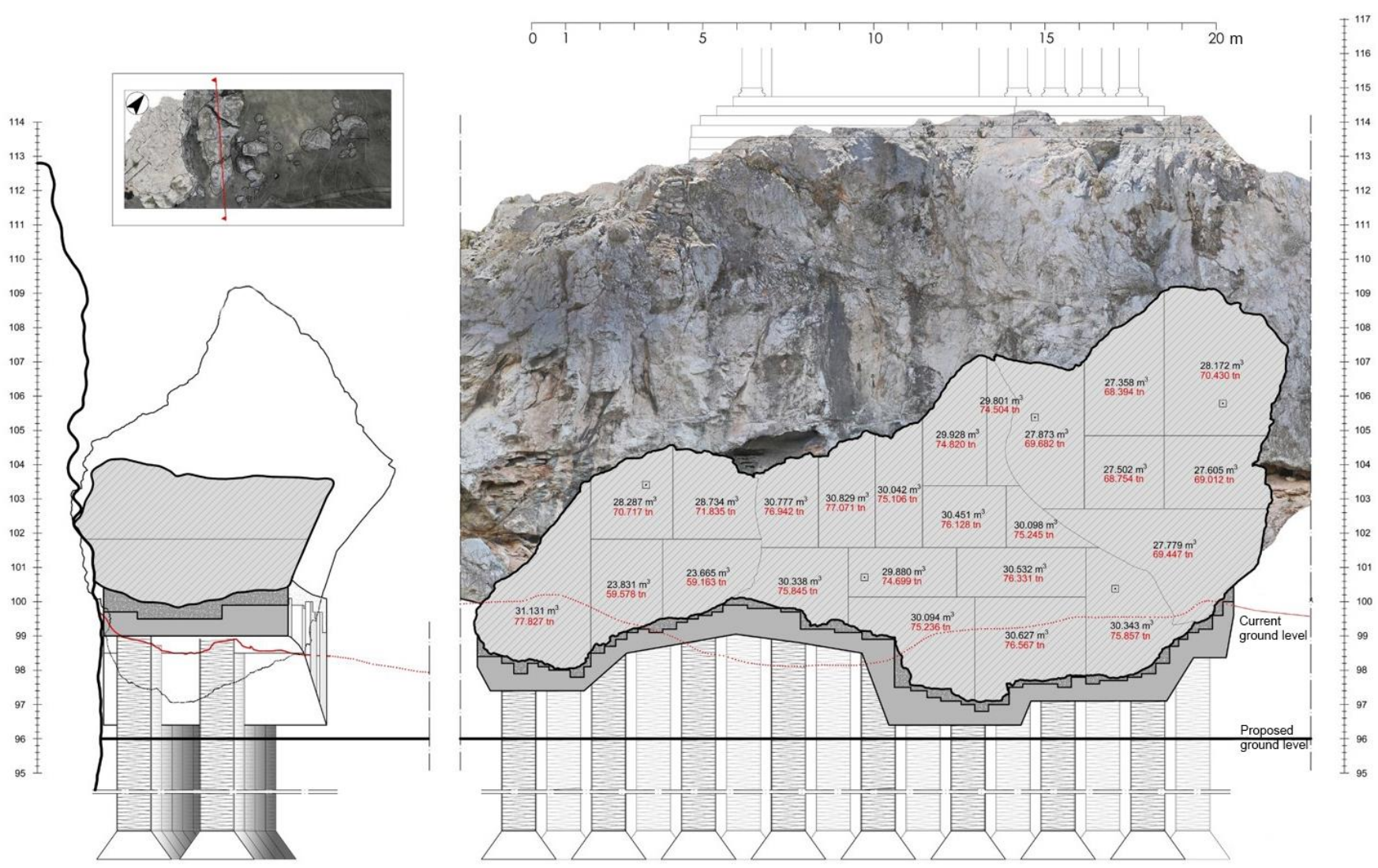

Figure 13: Segments from rocks 1A, 1B \& 1C placed on top of concrete substructure.

Finally, we have to elaborate more on the design of the upper surface of the substructure. The plans shown in Figures 12a and 12c contain:

- Contour lines exported from the aligned models of rocks $1 \mathrm{~A}$, $1 \mathrm{~B}$ and $1 \mathrm{C}$ with horizontal planes every $10 \mathrm{~cm}$.

- The boundaries of the rock segments from the bottom row.

- The center of gravity of each segment that was calculated automatically via Geomagic Studio.

- The positions of the jacks. Three jacks were placed within the boundaries of each segment. The formed triangle had to be almost equilateral and its center had to be close to the center of gravity of the segment, in order to avoid inversion, while the segment will be seated exclusively on the jacks.

- Horizontal zones with a defined elevation. Each part of the substructure, on which the corresponding rock segment would be seated, was divided to horizontal zones in order to: i) Be able to place the aluminum strips with the jacks and to remove them afterwards, ii) Resemble the surface of the rocks' bottom without being too complicated and expensive to construct.

The main difference of the two proposed surface designs is the direction that the jacks will be removed. The second design approached more efficiently the surface of the collapsed rocks. The recommended solution is presented in Figure 13.

\section{CONCLUSIONS}

The proposal of an integrated methodology for the relocation of collapsed rock segments to their original positions, was a very demanding task that required the combination of knowledge from numerous scientific disciplines. The use of advanced technology was not only extremely helpful but necessary. The virtual assembly and cutting of the rocks as well as the design of the substructure wouldn't be possible without the utilization of $3 \mathrm{~d}$ textured models.

The proposed methodology could be applied for the reconstruction of various monuments and other structures that aren't rock-cut or monolithic. For example, the virtual cutting, which is described in paragraph 3.4 , could be extremely useful while dealing with any kind of collapsed block that has to be divided before lifted, due to its great weight.

Finally, it has to be noted that the methodology will be evaluated and possibly improved after its application.

\section{ACKNOWLEDGEMENTS}

The authors would like to acknowledge the Ephorate of Antiquities of the City of Athens for granting us access at the archeological site of the Areopagus Hill, and the architect D. Bartzis for his contribution at the fieldwork.

\section{REFERENCES}

Andronopoulos, B. \& Koukis, G. 1976. Engineering geology study in the Acropolis area. Athens, Institute of Geology and Mineral Exploration.

Berg, L., 1978. The salvage of the Abu Simbel temples, Monumentum, Vol. 17.

Camp, J., 2004. The archaeology of Athens, Yale University Press.

Frantz, A., 1988. The Athenian Agora XXIV: Late Antiquity A.D. 267-700, American School of Classical Studies at Athens. 
Korres, M., 1996. Ein Beitrag zur Kenntnis der Attisch Ionischen Architektur. In: Schwandner, L. (ed.), Säule und Gebälk: zu Struktur und Wandlungsprozess griechischrömischer Architektur: Bauforschungskolloquium in Berlin vom 16. bis 18. Juni 1994 / veranstaltet vom Architekturreferat des DAI.

Lardinois, A., 1992. Greek myths for Athenian rituals: Religion and politics in Aeschylus' Eumenides and Sophocles' Oedipus Coloneus, Greek, Roman and Byzantine Studies, Vol. 33.

Stathi, K., 2014. The Carta Incognita of Ottoman Athens. In: Hadjianastasis M (ed.), Frontiers of the Ottoman Imagination Studies in Honour of Rhoads Murphey, Koninklijke Brill NV.

Acropolis Restoration Service, http://www.ysma.gr, Circuit Walls (last accessed 12/2018) 